\title{
Confrontation and Reconstruction of Beliefs and Attitudes towards Mathematics
}

\author{
Roland G. Pourdavood, Ph.D. and Xiongyi Liu, Ph.D. \\ Cleveland State Universit \\ Cleveland, Ohio, USA
}

\begin{abstract}
The problems of pre-service elementary teachers' (PSTs) lack of mathematics content knowledge and pedagogy are filled with complexity. Understanding this complexity and providing PSTs opportunities to experience meaningful mathematics learning may be a step towards PSTs mathematical empowerment. This mixed-method study investigates PSTs' prior mathematics learning experiences, beliefs and attitudes towards mathematics, and how these beliefs and attitudes are confronted and transformed during a semester-long methods course in mathematics. Data sources include survey questionnaires, PSTs' verbal and written responses to various classroom assignments and activities, classroom observations, and instructor's field notes. The findings of the study suggest that the PSTs' prior learning experiences vary across grade levels and are related to their self-reported beliefs and attitudes towards mathematics teaching and learning to a minimal extent. With a constructivist environment promoting critical reflections and classroom discussions, the methods course provides the PSTs opportunities to question their prior experiences and examine their beliefs and attitudes. However, this transformative experience of the PSTs is a complex process which requires an ongoing professional development and support. Engaging PSTs in action research in their own classrooms is a step towards mass access and equity in mathematics teaching and learning and transforming culture of mathematics teaching and learning in public schools.
\end{abstract}

Keywords: Pre-service teachers; Beliefs and attitudes; Mathematics teaching and learning; Constructivism; Transformative experience.

\section{Introduction}

The problem of pre-service elementary teachers' (PSTs') lack of content knowledge and pedagogical knowledge in mathematics is a complex and frustrating one (Lika, 2017; Whiren et al., 2014; Chen et al., 2014; Sivakova et al., 2017). This problem has its historical roots relative to PSTs' interactions and communication in mathematics classrooms from primary schools through the college (Saeed, Tahir, \& Latif, 2018; Livy, Muir, \& Sullivan, 2018). In this 
historical context, there is a need to research and report PSTs' stated expectations, attitudes, beliefs, and experiences during their k-12 schools and beyond. Furthermore, research is needed relative to how PSTs confront the above negative experiences through their critical reflections and how they may reconstruct their beliefs and attitudes towards teaching and learning mathematics. Critical reflections on teaching and learning, professional dialogue among PSTs, and supportive environment may encourage PSTs within a classroom community to take risks and look beyond a conventional point of view. Empowering mathematics PSTs who will work with students in various school districts is a step toward mass access to equitable mathematics education.

Gentile and Monaco (1986) expressed concern that learned-helplessness affects a student's attitudes in multiple areas, including student motivation, cognition, and emotions. Additionally, they propose that task importance, cues, and attribution style are three critical components that influence students to develop a learned-helplessness attitude. Findings from a study of 64 high school students who participated in timed multiplication problems suggested that repeatedly unsuccessful students resigned to a learned-helplessness state of mind. Moreover, Gentile and Monaco (1988) suggest that educators are in a position to positively influence student self-efficacy and how they perceive their competency. PSTs can be taught strategies to improve their abilities and thus, their self-confidence (Lee \& Hannafin, 2016). In higher education settings, instructors may create environments where the focus is on PSTs' efforts and their thinking processes, rather than on the final products (Ismajli \& ImamiMorina, 2018). Guiding PSTs to learn specific mathematics strategies in which they reflect and develop problem-solving, critical thinking, communication and mathematical representation may enhance their ability to overcome learned helplessness and transform their attitudes and beliefs towards mathematics.

To this end, the current study examines 76 PSTs' expectations, experiences, beliefs and attitudes towards learning mathematics during their k-12 schools and beyond. The primary research questions are, (1) what are the PSTs' prior expectations, experiences, beliefs, and attitudes towards mathematics learning? (2) How may these expectations, experiences, beliefs, and attitudes be transformed as they take a semester-long mathematics methods course? Understanding the above research questions and searching for possible explanations is significant for reforming mathematics teaching and learning and transforming culture of public school. In addition, collaboration between beginning teachers and more experience teachers in terms of instructional planning, cooperative teaching, and authentic assessment is vital for transforming culture of mathematics teaching, learning, and school reform. In what follows, we present a review of the literature relative to the study, theoretical framework, the context of the study, and methodology. Then we share the findings of the study followed by the discussions and concluding remarks. 


\section{Literature Review}

A deeper understanding of the process of teaching and learning through implementing evidence-based strategies can only be successful when PSTs reflect on the values and beliefs that they bring into a classroom. Stuart and Thurlow (2000) studied 26 PSTs to explore their beliefs about teaching and learning mathematics. This study was crucial because it helped PSTs realize the influence that their childhood experiences in education have on their teaching disposition. Through a series of interviews, reflective writing exercises, and final examination questions, PSTs recognized the pervasiveness personal experiences have in their preconceptions about mathematics teaching and learning. These exercises gave PSTs an outlet to self-reflect on how their perceptions impact classroom practices. Critical reflection is a quality that Yost, Sentner, and Forlenza-Bailey (2000) believe will guide PSTs towards higher-level thinking and reflection, supporting Stuart and Thurlow's (2000) assertion that PSTs benefit from connecting the practical experience to critical thought.

Teacher beliefs trickle down to students and strongly influence their perspective on learning. Kloosterman (1988) studied the relationship between student selfconfidence and their resulting reasoning for academic successes and failures based on attribution theory. This study derived the findings from self-reported student questionnaires with Likert-type scales in six areas of self-confidence and attribution styles. A sample population of 489 seventh-grade students in Indiana reported a correlation between student self-confidence in mathematics and thought processes regarding competence. In effect, if students reflect on their ability and believe in their success or failure, it will likely become a self-fulfilling prophecy.

Conversely, Schommer, Crouse, and Rhosed (1992) suggest that students who are confident in their ability based on memorization of knowledge (recitation of facts) are less competent in applying their new knowledge in related contexts. Two experiments were undertaken to collect and evaluate data: the first experiment collected data through a questionnaire that analyzed students' epistemological beliefs, and the second data set was collected through applied learning comparing the depth of student understanding. This comparison was evaluated based on students' abilities to either comprehend a mathematical text or communicate their comprehension. Researchers linked students' epistemological beliefs to their study habits, demonstrating how their approach to learning affects their comprehension directly. While this study used a sample of 424 Midwestern college students in the first experiment and 138 of those students in the second experiment, the results are ubiquitous through all academic levels. "If one truly believes that 'knowledge is a mere basket of facts', then one would presumably study so as to master lists of facts" (Schommer, Crouse, \& Rhosed, 1992, p. 441). Teachers model their beliefs and attitudes to students on a daily basis and must be acutely aware of the repercussions of those actions. Teaching students valuable study habits by maintaining high expectations in critical thinking from students will produce deeper learning. 
When does student learned-helplessness overpower teacher disposition? Can teachers alter a student's trajectory despite learned-helplessness in mathematics? Seligman, Maier, and Geer (1968) coined the term and defined learnedhelplessness as "the learning or perception of independence between the emitted response of the organism and the presentation and/or withdrawal of aversive events" (as cited in Dweck \& Reppucci, 1973, p. 109-110). Essentially learnedhelplessness is when a student believes that success and failure are outside their control, whereby external reinforcement responsibility is to blame, not effort. Diener and Dweck (1978) define learned-helplessness as "the perceived inability to surmount failure" (p. 451). Dweck and Reppucci (1973) measured the resiliency of 20 fifth-grade students to perform and exhibit effort on test and probe problems that were either soluble or insoluble. Based on a previous administration of the Intellectual Achievement Responsibility (IAR) Scale, the 20 students were scored on their beliefs of ability and effort and the connection to internal or external responsibility. There was a strong correlation between student IAR scores and their responsibility for failure. In a two-part follow-up study of 70 fifth-grade students and 60 fifth-grade students, respectively, Diener and Dweck (1978) found that students categorized as learned-helplessness by an IAR scale focused on causes of failure. In contrast the mastery-oriented category of students concentrated on finding solutions to the presented problems. Based on their findings, they recommend implementing teaching strategies that instruct learned-helplessness children to "focus on self-instructions and selfmonitoring" when faced with adversity (p. 460).

In a three-year longitudinal study of South Australian students ranging from third grade to seventh grade, students' learned-helplessness in mathematics were evaluated. Of the population that participated, teacher perceptions were the guiding force of the study. Learned-helplessness is defined by Yates (2009) as "student passivity resulting from changes in cognition and emotion, a loss of motivation, and a reduction in behavioral agency" (p. 87). She goes on to define mastery oriented students as those who "believe that success is determined by effort and are motivated, display more positive attitudes towards learning, use more effective learning and study strategies, and prefer challenging assignments" (p. 87). Convinced that "helplessness is a learned behavior that is amenable to change", Yates (2009) adapted the Student Behavior Checklist (SBC), "to evaluate the SBC as an accurate reflection of student identity of learned-helplessness or mastery oriented" (p. 88). Yates (2009) was able to positively correlate the SBC findings to student "motivation and achievement in mathematics" (p. 100). Identifying students who demonstrate learnedhelplessness traits in mathematics empowers teachers to intervene and foster a more positive attitude amongst students.

Reyes (1984) argues that for students to find success in mathematics, a balance of subject knowledge and a positive affective outlook are essential. McLeod (1992) recognizes the same needs for congruence of cognitive and affective requirements with regards to mathematics education for students. Reyes goes on to claim that learned-helplessness is just one subcomponent of how a student's affective development impacts mathematics learning. The four components that 
influence students' affective relationship with mathematics, according to Reyes (1984), are confident in learning mathematics, mathematics anxiety, attributions of success and failure in mathematics, and perceived usefulness of mathematics. In a thorough research overview, McLeod (1992) highlighted the national support for affective issues in mathematics teaching when citing how the National Council of Teachers of Mathematics (NCTM, 1989) and the National Research Council (NRC, 1989) emphasized recommendations for mathematics teachers to improve the affective attitude of students. Though difficult to measure quantitatively, a student's affective domain should be a primary concern for PSTs to implement practical methods that embrace effective support strategies. A mathematics teacher's role in the classroom must encompass the developmental needs of the students (Ismajli \& Imami-Morina, 2018; Sead, Jelena, \& Elvir, 2016; Kostelnik et al., 2015; Livy et al., 2018; Edwards, 2017; Kostos \& Shin, 2010).

Marshall (1994) examined the understandings of tasks that were purposeful learning by interviewing and observing kindergarten students from five classes. There was a consensus that children who have presented lessons with clear objectives by teachers were able to identify the learning purpose of the activity more readily. These clear objectives provide students with the tools to be successful. Further support from Schommer, Crouse, and Rhosed (1992) recognizes that epistemological beliefs represented by students' study habits are influenced by how their teacher models deep learning techniques in which they avoid circumscribed mathematics activities and assessments. Teachers and PSTs alike, "learn in social contexts in which they can interact and make sense of their experiences". (Maher \& Alston, 1990, p. 148) Maher and Alston (1990) observed New Jersey teachers engage in a two-fold project of practicing mathematics themselves and then interviewing a student. Their findings support social constructivist epistemology that learning and knowing are built by individuals as they participate in classroom activities.

Professional development for educators should be a continuous process whereby every experience translates a more profound understanding of pedagogical practice. Otherwise, teachers can perpetuate their own childhood experiences, as purported earlier by Stuart and Thurlow (2000). Teachers also participated in "task-based interviews [to direct their] attention to children's thinking", which led to a deeper understanding of children's cognitive processing in mathematics (Maher \& Alston, 1990, p. 157). The teachers shared that they dedicated time to developing relationships with students through informal interactions and by sharing personal anecdotes. Also, the teachers set expectations of student accountability when completing problems. Balancing affective and cognitive needs in mathematics instruction will help PSTs be better prepared to serve the needs of their students (Chen et al., 2014; Lika, 2017; Whiren et al., 2014; McAfee et al., 2016).

\section{Theoretical Framework and Context of the Study}

The social constructivist epistemology influences this research study in the areas of teachers' beliefs, attitudes, critical reflections, and their transformation. The 
social constructivist theory claims that an interactively open system such as learner must be understood through the process of the learner's interaction with the environment and other people. An interactively open system cannot be studied in isolation. The social constructivist theory recognizes the importance of individual identity, individual autonomy, and the notion of context. According to this theory, learning and knowing are built by individuals within the social and cultural milieu. The notion of experience and social interaction plays a pivotal role in constructivist theory (Cobb, Wood, \& Yackel, 1990; Cobb, 1994; Cobb \& Yackel, 1996; Shirvani, 2009; Steffe, 2016). Although the constructivist perspective has focused on understanding learners' mathematical knowing, it may offer insights as to how PSTs construct their ways of understanding about meaningful mathematics classroom practices. In particular, the social constructivism is utilized to examine the PSTs' expectations, experiences, beliefs, and attitudes towards teaching and learning mathematics.

This current study is conducted in an American university in the Midwest. The participants include 76 PSTs recruited from students enrolled in an early childhood mathematics methods course in conjunction with their practicum during fall 2017 and spring 2018. The participants were required to fulfill three mathematics prerequisite courses before taking this course. Although the participants have completed the three prerequisites with a grade of $\mathrm{C}$ or better, many of them still have low self-esteem as a mathematician and low selfconfidence for teaching mathematics in early childhood settings. As observed by the researcher/instructor of the course, students often enter this mathematics methods course believing that mathematics is something you either know or do not know, they are not good at mathematics, they cannot do mathematics, and they do not like mathematics.

For the instructor of the mathematics methods course, the first challenge is to provide the PSTs with opportunities to confront their negative beliefs and attitudes towards mathematics in a safe, non-judgmental environment so that they can free themselves from the fear of being evaluated towards self-critiquing and questioning their prior assumptions. Another challenge is to situate the classroom settings in a cooperatively and collaboratively manner so that the PSTs can communicate their reasoning and provide support for each other in mathematical problem-solving activities. In this sense, the instructor starts the course by posing interesting and open-ended mathematics problems that do not require memorization of mathematical facts or procedures for arriving at viable solutions. When the PSTs reach the realization that there are a variety of effective strategies for solving mathematical problems without much need for memorization, they become more confident and autonomous mathematics learners. They see themselves as members of a classroom community where mathematical knowledge is shared and co-constructed as an on-going collaborative process throughout the semester.

To address the two challenges indicated above, constructivist epistemology is applied to all aspects of classroom activities and instructional practices. The classroom instructor's intention is to create a learning environment where his 
PSTs can get a sense of constructivism in action. He employs several strategies consistent with constructivist epistemology. First, he uses small group cooperative learning for students to engage in meaningful discourse about mathematical reasoning. Second, he requires PSTs to write a novel and openended mathematical problem. Writing encourages PSTs' risk-taking and reflections. Third, he fosters autonomy among the PSTs by spending the first few weeks of class negotiating with them about roles and course expectations. Fourth, he communicates with his PSTs, telling them that they are capable mathematicians who can do mathematics and create relevant mathematical problems. Fifth, he encourages PSTs' dialogue and active listening. In problemsolving situations, he expects his PSTs to restate what the question is asking, articulate how they are interpreting the problem, model their solution, write about their thinking and reasoning, and compute. As the course evolves, through their experience in the methods class, the PSTs become the observer of themselves. They start questioning some of their earlier assumptions relative to teaching, learning, assessment, role of technology in the classroom, and classroom environments.

\section{Methodology}

In this study, we used a mixed-method approach, combining qualitative and quantitative methods for data collection and analysis. The mixed-method approach is recommended by many researchers (Briley, 2012; Burton, 2012; Cardetti \& Truxaw, 2014; Dreher et al., 2016). Our intension for using the mixedmethod approach was to achieve a better understanding and interpretation of PSTs' attitudes, beliefs, and experiences relative to mathematics teaching and learning, and how their attitudes and beliefs are confronted and transformed as they take mathematics methods courses in teacher education programs. The quantitative method allows the researchers to get a good sense of the PSTs' experiences, attitudes, and beliefs as they enter the methods course and make instructional decisions regarding where the PSTs are coming from and how they may gear classroom activities and assignments relative to the PSTs' background information and current needs. The qualitative dimension of the study provides an in-depth description of the PSTs' transformation of beliefs and attitudes towards mathematics teaching and learning and how the transformation occurs as a result of their new learning experience in the methods course.

The quantitative component of the study involves data collection via the administration of a questionnaire by the researchers at the beginning of the semester. Students were given one week to complete the questionnaire and bring it back to the class. The questionnaire consists of demographic questions, a measure of prior mathematics learning experiences, a measure of attitudes towards mathematics, and a measure of pedagogical beliefs about studentcentered teaching. The measure of prior mathematics learning experiences asks the PSTs to report the extent to which they used such strategies as memorization, technology, measurement, manipulatives, multiple representation, reading, discourse, illustration, and communication in the mathematics classes that they have attended. The measure of attitudes towards mathematics is comprised of three specific items of interest, motivation, and 
confidence. The measure of PSTs' beliefs about student-centered approaches in mathematics teaching and learning consists of six questions. All measures are Likert-type scales with satisfactory reliability. Both descriptive and inferential analyses were conducted with the survey data. The PSTs' self-reported experiences of various mathematics teaching and learning strategies were described across grade levels ranging from elementary school to college. The researchers then examined if such experiences were correlated with their beliefs and attitudes towards mathematics.

The qualitative portion of the methodology is influenced by constructivist inquiry (Guba \& Lincoln, 1989, 1994). In this portion of the study, we intend to describe and interpret the findings of the study. Data sources include university classroom observations and field notes, the PSTs' verbal and written responses to questions, oral and written discussions, reflections on reading assignments and course activities, presentations, and a final reflective paper. The data collection and data analysis co-occurred simultaneously using Guba and Lincoln's $(1989,1994)$ constant comparative method. We used the triangulation method for authenticity and trustworthiness. The triangulation of the study occurred in three ways. First, we triangulated the data with the participants before and after class for consistency and accuracy of our understanding and interpretations. The second triangulation of data occurred through interactions and communications between the researchers once a month. The third triangulation of data occurred via checking and examining the multiple data sources for consistency and accuracy of our understanding and interpretations. These triangulation processes were significant regarding the authenticity and trustworthiness of data analysis.

\section{Quantitative Findings/Results}

We conducted descriptive analysis of the nine types of PSTs'self-reported mathematics learning experiences (memorization, technology, measurement, manipulatives, multiple representation, reading, discourse, illustration, and communication) in the mathematics classes that they have attended during four stages of schooling (elementary school, middle school, high school, and college). The analysis indicates an interesting pattern in the frequency of each type of mathematics learning experience as the PSTs entered into higher educational stages. The use of discourse, reading, and communication as mathematics learning strategies showed a positive, linear trend from "rarely" in elementary school to somewhere between "sometimes" and "often" in college. The use of technology in a mathematics classroom showed the most dramatic increase from "rarely" in elementary school to somewhere between "often" and "always" in high school before it plateaued in college. The use of illustration and measurement gradually decreased from "often" in elementary school to "sometimes" in high school and college. The use of memorization and multiple representations stayed between "sometimes" and "often" with a trend of being slightly less frequent in elementary school and college but at a slightly higher frequency in middle school and high school. Finally, the use of manipulatives showed the most dramatic decrease from "often" in elementary school to "rarely" in high school and college. 
We then conducted a correlational analysis of the PSTs' mathematics learning experience and their current attitudes towards mathematics and pedagogical beliefs about student-centered learning. Although the attitudinal variables (interest, motivation, and confidence) were highly correlated amongst themselves, they were only related to two of the nine types of mathematics learning experiences. Specifically, the use of multiple representations was positively related to confidence $(r=.30)$, while the use of discourse was positively related to interest $(r=.32)$ and motivation $(r=.29)$. The PSTs' pedagogical beliefs about student-centered learning were unrelated to any previous mathematics learning experiences. No regression analysis was conducted due to the lack of significant correlations.

\section{Qualitative Findings/Results}

As the semester evolved, the PSTs reflected, discussed, and were actively engaged in various issues relative to constructivism, how children learn mathematics, teacher's role in the mathematics classroom, authentic assessment, the role of technology in mathematics classroom, and cooperative learning environment. Also, they expressed their main concerns and struggles. They shared their realizations relative to teaching and learning mathematics and stated their professional transformation. In what follows, we discuss these issues presented by the PSTs.

\section{Teaching and Learning Mathematics}

On the notion of students' mathematics learning, the PSTs reflected on their learning during their K-12 schools and discussed the limitations of direct instruction. They supported the ideas of constructivism, social interactions, and a cooperative learning environment.

"When I first began learning about various teaching methods, I struggled on two things. First was the idea of constructivism. This was a new concept to me because the majority of my own schooling involved a lot of worksheets and teacher-centered activities. I wondered how students were going to learn without an adult leading the activities or repetitious worksheets. For example, how can students learn multiplication facts without a paper full of multiplication problems? Second, I struggled with behavior management strategies. I was convinced that there were some students who would not pay attention or follow directions regardless of the situation. As I learned more about constructivism, I started to try different approaches in the classroom as a substitute teacher. This took a lot of trial and error, but it eventually taught me that fun and engaging activities can be a form of constructivist teaching when my role is to facilitate, observe, ask questions, and actively listen to my students' voices. Also, I found the wait time very important. When I ask questions, I should wait and give my students a chance to think and to respond." (PST's Reflection on Mathematics Learning)

The PSTs discussed their own experiences as students in the mathematics classrooms and the role of teacher for presenting meaningful tasks and creating 
classroom climate conducive to learning mathematics. For example, one of the PSTs shared her experience as a student learning mathematics.

"I was always someone who struggled in mathematics. In grade school, I was an average mathematics student. But once I got to middle school, I started to fall behind that I was getting Ds and Fs. Then I stopped doing my homework. In high school, I was placed in to the low-level math class. I truly feel that children learn mathematics best when they have proper support from a caring and patient teacher. I was someone who always asked "why" questions about mathematics, but many of those questions did not get answered by my teachers. I believe that children learn mathematics through inquiry-based environment. An inquiry-based learning environment is one where the students are responsible for asking questions and learning through their own construction and communication with peers." (PST's Reflection on Mathematics Learning)

The PSTs reflected on the teacher's role as a facilitator who presents meaningful tasks and provides students opportunities to make sense of their activity through cooperative learning, hands-on, manipulative tools, and technology. One PST explained the role of the teacher as follows:

"While the overarching goal of my instruction is for students to develop what I might refer to as a "mathematical mindset", my approaches to achieving this goal should be differentiated based on my familiarity with each student, not only their learning style, strengths or needs, but also their socio-cultural background. This means that if my primary goal is for students to perceive mathematics as an all-encompassing facet of their life and world, I must encourage a classroom in which mathematics is never far removed from the task or topic being assigned or discussed. In assisting and facilitating students with their learning as well as adhering to the principle ideas of constructivist learning, manipulatives can be used to establish and develop the concepts." (PST's Reflection on Mathematics Teaching)

The PSTs realized that teaching mathematics is not about giving the students the correct answers and hoping they remember them. "The important part is that students learn how to solve problems for themselves where it makes sense to them. I realized that teaching math should focus more on how students interpret the concepts rather than simply giving the correct answer. (PST's Reflection on Mathematics Teaching) As the PSTs worked through different problems in the methods class in their small groups and discussed their solution strategies during the whole class, they noticed that they retained the information better when they had to find solutions and verbally communicate how they reached that solution. The communication part was new to many of the PSTs because this was not how they experienced learning mathematics and how mathematics was taught to them. Problem-solving, reasoning, communication, both verbal and written, and mathematical representations through the use of manipulatives were new experiences for many of the participating PSTs. 


\title{
Authentic Assessment
}

The participating PSTs emphasized the value of communication, collaboration, active listening, constructivism, and the notion of culture for teaching mathematics. The topic of assessment was another critical issue. The PSTs challenged the limitations of standardized tests and supported more authentic assessment strategies. One PST put it this way:

\begin{abstract}
"Many teachers and pre-service teachers like myself find it difficult to reconcile their own personal beliefs about the assessment of student learning with those imposed on them by authorities at both the state and federal level. I will first start by saying that at a broad level, there appears to be a certain lack of trust afforded to teachers in expecting that they know their students best when it comes to abilities, needs and cultural/social background. With the increasing reliance on standardized tests, there has been an emergence of what I consider to be inaccurate and/or invalid assumptions made about student achievement and ability based on test outcomes. While few would argue the reliability of these tests, I believe that this reliability is the very reason that these tests do not truly measure the abilities of students in a way that informs effective instruction." (PST's Reflection on Mathematics Assessment)
\end{abstract}

The PSTs reflected on the severe consequences of these standardized tests on the students' social-emotional development in the primary grades. In acknowledging the conflicting expectations between the standardized tests and teacher's authentic assessments, the PSTs suggested a wide range of alternative assessments such as open-ended questions, students' mathematics journals, and portfolio evaluation.

\section{The Role of Technology in Mathematics Classroom}

The PSTs reflected and supported the technological tools for teaching and learning mathematics. They stated that as technology rapidly advances, it is the responsibility of the teacher to stay current with the implications of such innovations throughout their careers. For example, one PST reflected on the role of technology as follows:

"I often consider the effectiveness of various forms of technology being integrated into instruction/assessment prior to selecting them as appropriate tools for achieving learning goals and objectives. Educational technology today is abundant in both content and format, but often a thorough evaluation of how these tools will be used to ensure academic success and student achievement is required. Tools used to assist students with more basic computations such as calculators can present themselves as invaluable mechanisms for enhancing student's cognitive development in the way of processing and strategic thinking. Complex reasoning is facilitated in this way and the focus is more likely to be around strategic thinking and the processes students use in their problem solving rather than lower level skills such as simple operation." (PST's Reflection on Technology) 
In the context of inquiry-based learning through technology, the PSTs presented a variety of educational games and activities that are available to teachers to extend learning and promote mathematical investigation. Throughout the semester, they demonstrated how students maight be engaged in these platforms independently.

\section{Concerns and Struggles}

The participating PSTs reflected on the concerns and struggles for teaching mathematics in early childhood settings. One of the concerns/struggles mentioned by the PSTs was the balance between meaningful teaching/learning, and the state-mandated standardized tests.

"I often feel that I am expected to sacrifice the ideologies that comprise my framework for what I see as meaningful learning for the greater objective of high-stakes testing outcomes. I considered the practical application of these methods during my practicum experience. Along these lines, I might ask how I can maximize the use of my instructional time to focus on what I see as higher-level objectives while also allowing adequate time for students to learn the material with which they are presented. As a teacher, there are few feelings worse than knowing a child is being left behind because I am required to move at a pace that does not encourage teaching through understanding of crucial concepts or skills. It is worth noting that my limited freedom as a pre-service teacher in the field does not afford me the ability to tailor my instructional practices in a way that might address these concerns, but I do hope to observe the ways in which this type of exceptional instruction can be achieved during my student-teaching experience." (PST's Reflection on Concerns and Struggles)

Exposure to the various forms of alternative assessment during the semester has been helpful in delineate some of how the PSTs were able to adhere to their philosophy of teaching and maintaining the principles of what they saw as effective instruction and meaningful learning.

\section{The PSTs' Realizations}

One significant realization made by the PSTs was about the potential effect of unintentional language of "this problem is easy" or "this problem is not hard" on students' self-efficacy and, or their beliefs about their mathematics learning. One PST reflected this way:

"I distinctly remember a specific instance in which I told my secondgrade students during my practicum experience, "Oh, this one is easy, you guys got this!" While my intention was to relieve students of their fears or reservations about the specific concept, I now realize the likely implications of my naivety. While the purpose of my statement may have been realized by students initially, it is possible that it had the opposite effect on those students who began working through the concept with optimism but found it difficult or challenging after working through it for some time. This insensitivity is neglectful and has far-reaching 
consequences for later learning, instruction, and formation of student's self-perception." (PST's Reflection and Realization)

Through class discussions of this critical incident, the PST realized that while her students' abilities could be developed or improved through positive and caring attitudes in her approach to instruction, it was less likely that their talents would be changed based on her declaration that something was easy. Another vital realization made by the PSTs was the notion of actively listening and less talking. "I need to talk less and listen more. This is something that I neglect constantly." (PST's Reflection on Concerns and Struggles)

\section{Discussion}

This research study investigates the participating PSTs' prior expectations, experiences, beliefs, and attitudes towards mathematics during their primary grades, middle schools, and high school years. Also, the study examines how these prior experiences, beliefs, and attitudes may be deconstructed and transformed during a semester-long methods course in mathematics. The findings of the study suggest the PSTs' prior learning experiences vary across grade levels and are related to their self-reported beliefs and attitudes towards mathematics teaching and learning to a minimal extent. While the PSTs reported increasing use of discourse, reading, and communication as they went from elementary school to college, they also consistently reported frequent use of memorization throughout their schooling. The use of technology dramatically increased, whereas the use of manipulatives significantly decreased. The use of illustrations and measurements also gradually reduced, though, to a lesser extent. Most of the nine types of mathematics learning experiences were found to be unrelated to either attitudes towards mathematics or beliefs about mathematics teaching. Discourse and multiple representations were the only two exceptions, and even those correlations were of a smaller size. The findings indicate that attitudes towards mathematics learning were mostly unrelated to what types of mathematical tools and learning strategies the PSTs experienced. The strong beliefs about student-centered teaching held by the PSTs were not attributable to previous mathematics experience, either.

To facilitate meaningful learning of mathematical concepts and ideas, teachers should use a variety of tools and strategies at all educational levels. Therefore, we need to explore the reasons behind the findings of reliance on the use of memorization and reluctance to the use of manipulatives, illustrations, and measurements in our PSTs' previous mathematics learning experiences. It is possible that the PSTs' experiences in K-12 mathematics classrooms played a role in encouraging or modeling the use of some learning tools and strategies instead of others. To enable a change in the future, pre-service training and support are needed to help PSTs to confidently and effectively utilize and model the use of a wide range of mathematical learning tools and strategies. The ubiquitous availability of computer technology in today's schools and homes also indicates that technology integration may facilitate this process. For example, PSTs can learn more about the use of virtual manipulatives (Satsangi et al., 2016; MoyerPackenham et al., 2014). In addition, the mathematics learning tools and 
strategies discussed above can be and they should be used in combination with other educational approaches and activities such as collaborative learning, game-based learning, language art, and art education, interdisciplinary learning, complex problem solving, real-life connections, etc.

Furthermore, the findings of the study suggest the complex interplay of critical reflections, classroom discussions, and hand-on activities in a supportive setting; afforded the PSTs opportunities to become more aware of limitations of direct instruction. Most participating PSTs stated that their expectations, beliefs, and attitudes towards mathematics teaching and learning were transformed as a result of taking the mathematics methods course. They noted that the fundamental belief that all children can learn, especially when applied to mathematics, will always begin and be upheld with the reflection that is responsive and continuous. One PST presented her changed beliefs and attitudes this way:

"I was under the impression that math was a subject people were either inherently good or bad at. As someone who would be teaching math, I thought there would be students who just "don't get it" and there was only so much I could do. My attitude towards math was sort of indifferent. It wasn't a subject I ever looked forward to teaching or learning, but I understood that it was necessary to learn. Also, I had always expected that math would be the subject in which I would work with numbers only. I did not expect to do very much writing. Looking back on the semester, I think the changes in my beliefs and attitudes towards math came as a result of hands-on learning. While working with manipulatives and listening to various strategies from my classmates, I found myself very interested in the concepts. Writing also helped change my ideas of math. The more we wrote to communicate our thoughts, the more I realized that writing does have a purpose in learning math. Unlike my previous attitudes towards math, I am now more comfortable with teaching the subject. I look forward to the lessons I can create and implement in the future." (The PSTs Transforming Beliefs and Attitudes)

In general, the PSTs believe that children learn best when they do mathematics and when they have opportunities to interact with their environment and others. They made a clear connection between their transformed beliefs on children learning and constructivism. According to Morrison (2017), the constructivist theory "emphasizes the active role of children in developing their understanding and learning (p.18)". In other words, children will actively seek and construct knowledge and understanding of the world around them. Our study supports Morrison's assertion. For example, one of the PSTs expressed her transformed beliefs and attitudes as follows:

"I believe mathematics is taught and learned by allowing time. Children need time to explore, time to manipulate, time to explain, and time to think. Children should have the opportunity to come up with their own ways of solving problems through having small group time, 
manipulatives, and social interactions. When children are directly taught a concept and one way to solve a problem, that is what they study and master for a test and then the knowledge is lost. Instead, when children work in small groups, they have an opportunity to share ideas and listen to other ideas. Communication and explaining how the children came to their conclusions has a profound impact on construction of knowledge." (PST's Reflection and Transformation of Beliefs and Attitudes)

The PSTs reflected on the importance of visual representations and communication. They also reflected on the classroom teacher's role in establishing social norms of the classroom by valuing students' social and cultural backgrounds. "A classroom teacher needs to know where his/her students are coming from. 'You can't teach me if you don't know me'. He/she needs to learn his/her students' interest, abilities, learning style, and background". (PST's Transformation of Beliefs and Attitudes) The PSTs discussed the purpose of mathematics assessment as informing instruction and enhancing students' learning. The PSTs discussed their feeling of frustration relative to the state-mandated standardized tests. "I must stress my frustration about the state tests. The tests measure what students cannot do. However, as a teacher, my job is to find what students can do and how I can help them to do better". (PST's Reflection on Assessment) The PSTs emphasized that teachers ought to aim to use assessment strategies that are authentic and meaningful. Some characteristics of authentic assessment expressed by the PSTs include performance-based assessment, teacher's observations, and field notes, projects, and portfolio assessment.

Another issue discussed by the PSTs was the role of technology in early childhood classroom. The PSTs overwhelmingly supported the idea of technological tools such as computers and calculators for teaching mathematics. The PSTs were strong advocates for the integration of technology in the mathematics classroom. They connected the ideas of constructivism, where students build their knowledge and have autonomy for their learning. Although the vast majority of the PSTs were supportive of technology in the early childhood classroom, some of them were not supportive of using calculators in the classroom.

"While I support technology use in the math classroom, I believe the use of calculators should be limited in the early childhood classroom. Children should spend their early years learning how to solve basic math problems without the help of a calculator. Teachers should be taking this time to ensure that children are developing their own strategies for problem solving. If they start too early with calculators, it is possible that students will never fully grasp these mathematical concepts which could hinder them later on in their schooling." (PST's Reflection on Technology) 


\section{Concluding Remarks}

The PST's transformation of beliefs and attitudes towards mathematics teaching and learning was complex process. It is challenging to pinpoint with certainty when and how exactly the turning points in the PSTs' beliefs and attitudes occurred. However, we can state with confidence that the complex interplay of critical reflections, classroom assignments and activities, small group cooperative learning, verbal and written communication, manipulatives, and technology provided the PSTs opportunities to confront with their prior assumptions, beliefs and attitudes; and transform their beliefs and attitudes towards teaching and learning mathematics consistent with constructivist epistemology and the $\operatorname{NCTM}(2000,1995, \& 1991)$ recommendations.

Sustaining PSTs' positive beliefs and attitudes toward mathematics teaching and learning necessitate consistent and coordinated efforts on several different levels. First, it requires an on-going partnership between universities and public school settings, where university faculty interact with public school teachers, particularly newer teachers, in action research. This collaborative action research is a step toward transforming the culture of mathematics teaching and learning in public schools. This partnership between universities and public schools is a moral obligation of higher education. Second, pairing and engaging newer teachers with more transformative experienced teachers through collaborative activities for designing curriculum, planning instruction, and developing assessment strategies is crucial for mentoring relationships. Exchanging ideas and information between newer teachers and experienced teachers has the potential for preparing organizational leadership opportunities. Third, providing teachers, particularly beginning teachers, with opportunities to become involved in local, regional, and national conferences such as NCTM and other related organizational conferences for sharing ideas and engaging in dialogues with their colleagues is pivotal for sustaining this culture of transformation. This sustainability strategy is a step toward mass access and equity in mathematics education, and it has social justice implication.

\section{References}

Briley, J. S. (2012). The relationships among mathematics teaching efficacy, mathematics self-efficacy, and mathematical beliefs for elementary pre-service teachers. Issues in the Undergraduate Mathematics Preparation of School Teachers, 5, 1-13.

Burton, M. (2012). What is math? Exploring the perception of elementary pre-service teachers. Issues in the Undergraduate Mathematics Preparation of School Teachers, 5, 1-17. Retrieved from https:/ / files.eric.ed.gov/fulltext/EJ970350.pdf

Cardetti, F., \& Truxaw, M. P. (2014). Toward improving the mathematics preparation of elementary pre-service teachers. School Science and Mathematics, 114(1), 1-9.

Chen, J., McCray, J., Adams, M., \& Leow, C. (2014). A survey study of early childhood teachers' beliefs and confidence about teaching early math. Early Childhood Education Journal, 42(6), 367-377. doi:10.1007/s10643-013-0619-0

Cobb, P. (1994). Where is mind? Constructivist and sociocultural perspectives on mathematical development. Educational Researcher, 23(7), 13-20. doi:10.2307/1176934

Cobb, P., \& Yachel, E. (1996). Constructivist, emergent, and sociocultural perspectives in the context of developmental research. Educational Psychologist, 31(3/4), 175-190. doi:10.1080/00461520.1996.9653265 
Cobb, P., Wood, T., \& Yackel, E. (1990). Classroom as learning environments for teachers and researchers. Journal for Research in Mathematics Education, Monograph, 4, 125$146 \& 195-210$.

Diener, C. I., \& Dweck, C. S. (1978). An analysis of learned helplessness: Continuous changes in performance, strategy, and achievement cognitions following failure. Journal of Personality and Social Psychology, 36(5), 451-462. doi:10.1037//0022-3514.36.5.451

Dreher, A., Kuntze, S., \& Lerman, S. (2016). Why use multiple representations in the mathematics classroom? Views of English and German pre-service teachers. International Journal of Science $\mathcal{E}$ Mathematics Education, 14, 363-382. doi:10.1007/s10763-015-9633-6

Dweck, C., \& Reppucci, D. (1973). Learned helplessness and reinforcement responsibility in children. Journal of Personality and Social Psychology, 25(1), 109-116. doi:10.1037/h0034248

Edwards, S. (2017). Play-based learning and intentional teaching: Forever different. Australian Journal of Early Childhood, 42(2), 4-11. doi:10.23965/ajec.42.2.01

Gentile, J. R., \& Monaco, N. M. (1986). Learned helplessness in mathematics: What educators should know. The Journal of Mathematical Behavior, 5(2), 159-178.

Gentile, J. R., \& Monaco, N. M. (1988). A learned helplessness analysis of perceived failure in mathematics. Focus on Learning Problems in Mathematics, 10(1), 15-28.

Guba, E. G.,\& Lincoln, Y. S. (1994). Comparing paradigm in qualitative research. In N. K. Denzin \& Y. S. Lincoln (Eds.), Handbook of qualitative research (pp.105-117). Thousand Oaks, CA: Sage.

Guba, E. G., \& Lincoln, Y. S. (1989). Fourth generation evaluation. Newbury Park, CA:Sage.

Ismajli, H., \& Imami-Morina, I. (2018). Differentiated instruction: Understanding and applying interactive strategies to meet the needs of all students. International Journal of Instruction, 11(3), 207-218. doi:10.12973/iji.2018.ii315a

Kloosterman, P. (1988). Self-confidence and motivation in mathematics. Journal of Educational Psychology, 80(3), 345-351. doi:10.1037//0022-0663.80.3.345

Kostelnik, M. J., Soderman, A. K., \& Whiren, A. P., \& Rupiper, M. L. (2015). Developmentally appropriate curriculum: Best practices in early childhood education (6th ed.). Upper Saddle River, NJ: Pearson.

Kostos, K., \& Shin, E. (2010). Using math journals to enhance second grades' communication of mathematics thinking. Early Childhood Education Journal, 38(3), 223-231. doi:10.1007/s10643-010-0390-4

Lee, E., \& Hannafin, M. (2016). A design framework for enhancing engagement in student-centered learning: Own it, learn it, and share it. Education Technology Research and Development, 64(4), 707-734. doi:10.1007/s11433-015-9422-5

Lika, M. (2017). The impact of curricula and lesson planning in the teaching process. Academic Journal of Business, Administration, Law, and Social Science, 3, 240-247.

Livy, S., Muir, T., \& Sullivan, P. (2018). Challenging tasks lead to productive struggle. Australian Primary Mathematics Classroom. 23(1), 19-24.

Maher, C., \& Alston, A. (1990). Chapter 10: Teacher development in mathematics in a constructivist framework. Journal for Research in Mathematics Education. Monograph, 4, 147-210. doi:10.2307/749918

Marshall, H. H. (1994). Children's understanding of academic tasks: Work, play, or learning. Journal of Research in Childhood Education, 9(1), 35-46. doi:10.1080/02568549409594951

McAfee, O., Leong, D. J., \& Bodrova, E. (2016). Assessing and guiding young children's development and learning ( $6^{\text {th }} E d$.). Upper Saddle River, NJ: Pearson.

McLeod, D. B. (1992). Research on affect in mathematics education: A reconceptualization. In D. A. Grows (Ed.), Handbook of Research on Mathematics Teaching and Learning (pp. 575-596). New York: Macmillan. 
Morrison, G. S. (2017). History and theories: Foundations for teaching and learning. Fundamentals of Early Childhood Education (pp. 66-103). Boston: Pearson.

Moyer-Packenham, P. S., Baker, J., Westenskow, A., Anderson-Pence, K. L., Shumway, J. F., \& Jordan, K. E. (2014). Predictors of achievement when virtual manipulatives are used for mathematics Instruction. REDIMAT - Journal of Research In Mathematics Education, 3(2), 121-150.

National Council of Teachers of Mathematics (2000). Principles and standards for school mathematics. Reston, VA: NCTM.

National Council of Teachers of Mathematics (1995). Assessment standards for School mathematics. Reston, VA: NCTM.

National Council of Teachers of Mathematics (1991). Professional standards for teaching mathematics. Reston, VA: NCTM.

National Council of Teachers of Mathematics (1989). Curriculum and evaluation standards. Reston, VA: NCTM.

National Research Council (1989). Everybody counts: A report to the nation on the future of mathematics Education, Reston, AV: NCTM.

Reyes, L. H. (1984). Affective variables and mathematics education. The Elementary School Journal, 84(5), 558-581. doi:10.1086/461384

Saeed, M., Tahir, H., \& Latif, I. (2018). Teachers' perceptions about the use of classroom assessment techniques in elementary and secondary schools. Bulletin of Education and Research, 40(1), 115-130.

Satsangi, R., Bouck, E. C., Taber-Doughty, T., Bofferding, L., \& Roberts, C. A. (2016). Comparing the effectiveness of virtual and concrete manipulatives to teach algebra to secondary students with learning disabilities. Learning Disability Quarterly, 39(4), 240-253. doi:10.1177/0731948716649754

Schommer, M., Crouse, A., \& Rhodes, N. (1992). Epistemological beliefs and mathematical text comprehension: Believing it is simple does not make it so. Journal of Educational Psychology, 84(4), 435-443. doi:10.1037//0022-0663.84.4.435

Sead, R., Jelena, S., \& Elvir, C. (2016). Cooperative approach to learning in mathematics. Human Research in Rehabilitation, 6(1), 109-125.

Shirvani, H. (2009). Does your elementary mathematics methodology class correspond to constructivist epistemology? Journal of Instructional Psychology, 36(3), 245-258.

Sivakova, D., Kochoska, J., Ristevska, M., \& Gramatkovski, B. (2017). ICT- The Educational programs in teaching mathematics. TEM Journal, 6(3), 469-478. doi:10.18421/TEM63-06

Steffe, L. P. (2016). Toward a model of constructivist mathematics teaching. Constructivist Foundations, 12(1), 75-77. doi:10.2307/749206

Stuart, C., \& Thurlow, D. (2000). Making it their own: Pre-service teachers' experiences, beliefs, and classroom practices. Journal of Teacher Education, 51(2), 113-121. doi:0.1177/002248710005100205

Whiren, A. P., Soderman, A. K., Kostelnik, M. J., \& Rupiper, M. (2014). Developmentally appropriate curriculum: Best practices in early education (6th ed.). Upper Saddle River, NJ: Pearson/Prentice Hall.

Yates, S. (2009). Teacher identification of student learned helplessness in mathematics. Mathematics Education Research Journal, 21(3), 86-106. doi:10.1007/bf03217554

Yost, D. S., Sentner, S. M., \& Forlenza-Bailey, A. (2000). An examination of the construct of critical reflection: Implications for teacher education programming in the 21st century. Journal of Teacher Education, 51(1), 39-49. doi:10.1177/ 002248710005100105 